www.jmscr.igmpublication.org

Impact Factor 5.84

Index Copernicus Value: 71.58

ISSN (e)-2347-176x ISSN (p) 2455-0450

crossref DOI: _https://dx.doi.org/10.18535/jmscr/v5i11.205

Journal Of Medical Science And Clinical Research

\title{
A Comparative Study between Pure Tone Audiometry and Impedance Audiometry Findings in Patients with Chronic Retracted Tympanic Membranes
}

\author{
Authors \\ Priyank D. Talati ${ }^{1}$, Kalpana Rajiv Kumar ${ }^{2}$, Paulastya Ghosh $^{3}$ \\ ${ }^{1}$ Junior Resident, Department of ENT, MGM Medical College and Hospital, Navi Mumbai, 9867030479 \\ ${ }^{2}$ Professor and Head of Department, Department of ENT, MGM Medical College and Hospital, Navi \\ Mumbai, 9821548296 \\ ${ }^{3}$ Junior Resident, Department of ENT, MGM Medical College and Hospital, Navi Mumbai, 8691807183 \\ Email:'priyanktalati@yahoo.com, ${ }^{2}$ kalp64@hotmail.com, ${ }^{3}$ paulastyaghosh@hotmail.com \\ Corresponding Author \\ Priyank D. Talati \\ 702, Himanshu Mandar, Opposite Surya Hospital, Lallubhai Park Road Extension, Vile Parle (W), \\ Mumbai-400056

\begin{abstract}
Chronic cases of retracted tympanic membranes are common conditions which present to the ENT OPD. They are due to a variety of middle ear pathologies and present with decreased hearing in a majority of cases. Pure tone audiometry and tympanometry are the two most common types of audiological evaluations performed in an ENT OPD. They can predict the ossicular chain status and the status of the middle ear as a result of their interpretations. In this study done on 25 patients with chronic retracted tympanic membranes, we established a statistically significant correlation between Grade of Retraction and hearing loss ( $p=$ $0.0389)$ and between tympanometry and pure tone audiometry $(p=0.000402)$.

Keywords: Pure tone audiometry, Tympanometry, Retracted Tympanic Membrane.
\end{abstract}

\section{Introduction}

Tympanic membrane retraction describes a condition in which a part of the eardrum lies deeper within the ear than its normal position. The eardrum comprises of two parts, the pars tensa, which is the main part of the eardrum, and the pars flaccida, which is a smaller part of the eardrum located above the pars tensa. Either or both parts may become retracted. The various stages of Secretory Otitis Media where a retracted tympanic membrane is a classical examination are as follows.
1. Eustachian Tube Catarrh: It occurs due to chronic inflammation of the Eustachian Tube which prevents it proper function leading to generation of negative pressure in the middle ear.

2. Otitis Media with Effusion (OME): Here there is an accumulation of fluid inside the middle ear cavity which occurs due to negative pressure in the middle ear which hampers its drainage.

3. Atrophic Tympanic Membrane: Due to long standing negative pressure in the 
middle ear, the circular fibres which impart strength to the tympanic membrane get atrophied leading to atrophic changes in the Tympanic Membrane.

4. Atelectasis of the Tympanic Membrane: Here due to further atrophy of the tympanic membrane there occurs diffuse retraction of the tympanic membrane towards the promontory.

5. Adhesive Otitis Media: Due to the atelectatic tympanic membrane and due to increased negative pressure in the middle ear, the mobility of ossicles and the membrane is diminished and stiffness and rigidity of ossicles occurs.

6. Tympanosclerosis: Here, due to chronic inflammation and negative pressure generated in the middle ear, increased fibroblast activity results in deposition of collagen.

7. The terms "atelectasis" or sometimes "adhesive otitis media" can be used to describe retraction of a large area of the pars tensa. Attempts have been made to categorise the extent of tympanic membrane retraction (1-3) though the validity of these classifications is limited (4). However, the most commonly used classification for these Tympanic membrane retraction is Sade's Classification ${ }^{(1)}$.

\begin{tabular}{|l|c|c|}
\hline $\begin{array}{l}\text { Grade of } \\
\text { Retraction }\end{array}$ & Title & Description \\
\hline 1 & $\begin{array}{c}\text { Retracted } \\
\text { ear }\end{array}$ & $\begin{array}{c}\text { Slight retraction of tympanic } \\
\text { membrane }\end{array}$ \\
\hline 2 & $\begin{array}{c}\text { Severe } \\
\text { retraction }\end{array}$ & $\begin{array}{c}\text { Retraction of the tympanic } \\
\text { membrane, touching the incus } \\
\text { or the stapes }\end{array}$ \\
\hline 3 & Atelectasis & $\begin{array}{c}\text { Tympanic membrane } \\
\text { touching the promontory }\end{array}$ \\
\hline 4 & $\begin{array}{c}\text { Adhesive } \\
\text { otitis }\end{array}$ & $\begin{array}{c}\text { Tympanic membrane } \\
\text { adherent to the promontory }\end{array}$ \\
\hline
\end{tabular}

The retracted part of the tympanic membrane may become adherent to structures in the middle ear, which hinders spontaneous resolution. Ingress of the retractions deep into the ear can cause erosion of the bone. The ear drum has to retract minimally to come in contact with the bony structures of the middle ear such as the ossicles. Along with ossicular erosions, the scutum and the thick bone covering the cochlea (the promontory) can get eroded. As skin cells die they form a barrier of dry protein called keratin. This layer of keratin is normally pushed out of the ear by migration of skin cells along the ear canal and is turned into wax. Clearance of keratin can be disrupted by tympanic membrane retraction so that keratin accumulates within the retraction pocket. When keratin becomes trapped deep inside the ear and cannot be cleaned out, it is known as cholesteatoma. Growth of bacteria in the trapped keratin causes smelly discharge from the ear and can spread to cause serious infection.

A majority of the patients who present with tympanic membrane retractions have no clinical symptoms. A great number of cases of tympanic membrane retractions resolve spontaneously, such that the tympanic membrane becomes normal again $^{(5)}$. In patients with chronic retracted tympanic membranes, permanent hearing loss can occur due to ossicular chain destruction.

Pure tone audiometry (PTA) is the key hearing test used to identify hearing threshold levels of an individual, enabling determination of the degree, type and configuration of a hearing loss. It provides a basis for the diagnosis and management of patients with hearing loss. It is a subjective assessment of a patients hearing threshold as it relies on a patient's response to pure tone stimuli. Conventional audiometry tests frequencies between 250 hertz $(\mathrm{Hz})$ and $8 \mathrm{kHz}$, whereas high frequency audiometry tests in the region of $8 \mathrm{kHz}-16 \mathrm{kHz}$. Hearing loss is classified into mild hearing loss $(26-40 \mathrm{~dB})$, moderate hearing loss (41-55 dB), moderately severe hearing loss (56-70 dB), severe hearing loss (71$90 \mathrm{~dB})$ and profound hearing loss $(>90 \mathrm{~dB})$ on the basis of pure tone audiometry ${ }^{(6)}$.

Tympanometry is an examination used to test the condition of the middle ear and mobility of the eardrum (tympanic membrane) and the conduction bones by creating variations of air pressure in the 
ear canal ${ }^{(7)}$. Tympanometry is not a hearing test, but it is an objective test of middle ear function. It measures the transmission of energy through the middle ear. It should always be used in concomitance with pure tone audiometry. It should not be used to assess the sensitivity of hearing. It helps us in distinguishing between sensorineural and conductive hearing loss especially when it is not distinguishable with help of Weber's and Rinne's tests. It can help in making a diagnosis of otitis media by demonstrating middle ear effusion.

Furthermore, in a primary care setting, tympanometry can be helpful in making the diagnosis of otitis media by demonstrating the presence of a middle ear effusion. In it, a $226 \mathrm{~Hz}$ tone generated by tymanometer strikes the tympanic membrane which causes vibration of the middle ear, resulting in a perception of hearing. A small amount of sound is reflected back which is detected by the instrument. A majority of the middle ear problems result in the stiffening of the middle ear, which causes more sound to be reflected back. The instrument measures the reflected sound and expresses it as an admittance or compliance, plotting the results on a chart known as a tympanogram. Admittance is a measurement of how sound is reflected back. In normal circumstances, the air pressure in the external auditory canal is equivalent to ambient air pressure. Also, the middle ear air pressure is approximately equivalent to the ambient pressure due to the periodic opening of the eustachian tube in the middle ear, which helps to equalize air pressure. The maximum sound is transmitted through the middle ear cleft when ambient air pressure is equal to pressure in the middle ear cleft. Tympanograms are categorized according to the shape of the plot. Tympanogram tracings are classified as type A (normal), type B (flat, clearly abnormal), and type $\mathrm{C}$ (indicating a significantly negative pressure in the middle ear, possibly indicative of pathology ${ }^{(8)}$. Type $\mathrm{A}$ is further divided into two subtypes namely $A_{s}$ and $A_{d}$. $A_{s}$ is seen when compliance is lower at or near ambient air pressure. It is seen in fixation of ossicles. $A_{d}$ is seen when there is high compliance at or near ambient pressure, seen in ossicular discontinuity or thin and laxtympanic membrane.

Here we examine the relationship between pure tone audiometry findings and tympanometry findings and try to evaluate if the tympanometry findings corroborate with pure tone audiometry findings in terms of hearing loss. We also tried to establish a relationship between grades of tympanic membrane retraction and hearing loss on audiometry, and between retraction and tympanograms.

\section{Materials and Methods}

This study was conducted on a total of 25 patients who presented to the ENT OPD of a tertiary hospital in Navi Mumbai. Written informed consent was taken from all patients. Study was conducted between the period of May 2017 to October 2017. All the patients selected for the study had chronic ( $>3$ months) retracted tympanic membranes and all of them complained of hearing loss. All the patients considered for this study had only pars tensa retraction on examination. Patients were selected between the age of 18-55 years. None of the patients selected for the study had sensorineural hearing loss nor did they have any prior history of ear discharge. All patients had their history taken in detail. Then they underwent otoscopic examination to evaluate their tympanic membranes. The retraction of the tympanic membranes was classified on the basis of Sade's Classification ${ }^{(1)}$.Patients then underwent a pure tone audiometry and their hearing loss was classified into mild, moderate, moderately severe, severe and profound as per WHO classification ${ }^{(6)}$. Patients then underwent an impedance audiometry to evaluate the compliance of their tympanic membranes. The curves were $\mathrm{A}, \mathrm{A}_{\mathrm{s}}, \mathrm{A}_{\mathrm{d}}, \mathrm{B}$ and $\mathrm{C}$ (8). The audiometer used was a ELKON EDA $3 \mathrm{~N} 3$ model audiometer and the tymanometer used was a MAICO MI 24 model audiometer.

The data so collected was tabulated on Microsoft Office Excel 365. The frequencies of hearing loss, 
tympanograms and the grades of retractions were calculated and the relationships between them were tabulated. The p-values were calculated between tympanometry, pure tone audiometry and the grades of retraction to establish the strength of association between them.

\section{Results}

25 patients were a part of the study. The average age of patients involved in the study was 32.04. 16 (64\%) males and $9(36 \%)$ females were a part of this study with a $\mathrm{M}$ : $\mathrm{F}$ ratio of 1.77 . All the patients involved in the study had chronic retracted tympanic membrane. $14(56 \%)$ patients had right sided retraction and 11(44\%) had left sided retraction. No patients included in the study had bilateral retraction.

\section{A) Types of Retractions seen as per Sade's Classification}

The patient's retractions were then classified based on Sade's Classification. Type 3 was the most commonly seen in $9(36 \%)$ and Type 4 was the least common seen in $3(12 \%)$ patients.

Table 1: Classification of Patients as per Sade's Classification $^{(1)}$.

\begin{tabular}{|l|c|}
\hline Grade of Retraction & Number $(\mathrm{n}=25)$ \\
\hline Grade 1 & $7(28 \%)$ \\
\hline Grade 2 & $6(24 \%)$ \\
\hline Grade 3 & $9(36 \%)$ \\
\hline Grade 4 & $3(12 \%)$ \\
\hline
\end{tabular}

\section{B) Types of Hearing Loss seen.}

The patient's degree of hearing loss was classified based on the WHO classification for hearing loss. The most commonly seen type of hearing loss seen was moderate seen in $12(48 \%)$ cases and the least commonly type seen of hearing loss was moderately severe seen in Type 6 (24\%).

Table 2: Classification of Patients as per Hearing Loss ${ }^{(6)}$.

\begin{tabular}{|l|c|}
\hline Severity of Hearing Loss & Number \\
\hline Mild & $7(28 \%)$ \\
\hline Moderate & $12(48 \%)$ \\
\hline Moderately Severe & $6(24 \%)$ \\
\hline
\end{tabular}

\section{C) Types of Tympanometry Curves seen.}

The patients included in the study were also classified based on the tympanometry curve. Type $\mathrm{C}$ was the most common seen in $9(36 \%)$ cases and Type $\mathrm{A}_{\mathrm{s}}$ seen in $2(8 \%)$ patients was the least common type of tympanometry curve.

Table 3: Classification of Patients based on Tympanometry Curve ${ }^{(8)}$

\begin{tabular}{|l|c|}
\hline Type of Curve & Number \\
\hline $\mathrm{A}_{\mathrm{s}}$ & $2(8 \%)$ \\
\hline $\mathrm{A}_{\mathrm{d}}$ & $7(28 \%)$ \\
\hline $\mathrm{A}$ & $4(16 \%)$ \\
\hline $\mathrm{B}$ & $3(12 \%)$ \\
\hline $\mathrm{C}$ & $9(36 \%)$ \\
\hline
\end{tabular}

\section{D) Co-relation between Grade of Retraction and Tympanometry Curve}

7 patients included in the study had Grade 1 retraction and amongst them, the most common type of tympanometry curves obtained were $A_{d}$ and $\mathrm{C}$, obtained in 2 patients each.

6 patients included in the study had Grade 2 retraction and amongst them, the most common type of tympanometry curve was Type $\mathrm{C}$, seen in 3 patients.

9 patients included in the study had Grade 3 retraction and amongst them, the most common type of tympanometry curve was $A_{d}$ seen in 4 patients.

3 patients included in the study had Grade 4 retraction and amongst them, the most common type of tympanometry curve was A, B and C seen in one patient each.

The p-value between grade of retraction and the tympanometry curve was 0.87758605 (p-value < 0.05 is statistically significant), hence there is no statistical association between the two entities.

Table 4: Co-relation between Grade of Retraction and Tympanometry Curve.

\begin{tabular}{|l|c|c|c|c|c|}
\hline \multirow{2}{*}{} & \multicolumn{5}{|c|}{ Types of Tympanometry } \\
\cline { 2 - 6 } & $\mathrm{A}_{\mathrm{s}}$ & $\mathrm{A}_{\mathrm{d}}$ & $\mathrm{A}$ & $\mathrm{B}$ & $\mathrm{C}$ \\
\hline Grade of Retraction & & & & & \\
\hline 1 & 1 & 2 & 1 & 1 & 2 \\
\hline 2 & 0 & 1 & 1 & 1 & 3 \\
\hline 3 & 1 & 4 & 1 & 0 & 3 \\
\hline 4 & 0 & 0 & 1 & 1 & 1 \\
\hline
\end{tabular}


E) Co-relation between Grade of Retraction and Hearing Loss.

Out of the 7 patients in this study with Grade 1 retraction, mild and moderate hearing loss were the most common types of hearing loss seen in 3 patients each.

Out of the 6 patients in this study with Grade 2 retraction, moderately severe hearing loss was the most common type of hearing loss seen in 3 patients

Out of the 9 patients in this study with Grade 3 retraction, moderate hearing loss was the most common type of hearing loss seen in 8 patients.

Out of the 3 patients in this study with Grade 4 retraction, mild hearing loss was the most common type of hearing loss seen in 4 patients.

The $p$-value between grade of retraction and hearing loss is 0.0389 ( $\mathrm{p}$-value $<0.05$ is statistically significant), hence there is a statistical co-relation between the two entities.

Table 5: Co-relation between Grade of Retraction and Hearing Loss.

\begin{tabular}{|l|c|c|c|}
\hline \multirow{2}{*}{} & \multicolumn{3}{|c|}{ Types of Hearing Loss (On PTA) } \\
\cline { 2 - 4 } & Mild & Moderate & $\begin{array}{c}\text { Moderately } \\
\text { Severe }\end{array}$ \\
\hline $\begin{array}{l}\text { Grade of } \\
\text { Retraction }\end{array}$ & & & \\
\hline 1 & 3 & 3 & 1 \\
\hline 2 & 2 & 1 & 3 \\
\hline 3 & 0 & 8 & 1 \\
\hline 4 & 2 & 0 & 1 \\
\hline
\end{tabular}

\section{F) Co-relation between Tympanometry and}

\section{Pure Tone Audiometry}

Out of the 2 patients in this study with $\mathrm{A}_{\mathrm{s}}$ type of tympanometry curve, both patients had moderate hearing loss.

Out of the 7 patients in this study with $A_{d}$ type of tympanometry curve, moderate hearing loss was the most common seen in 6 patients.

Out of the 4 patients in this study with A type of tympanometry curve, mild hearing loss was the most common seen in 3 patients.

Out of the 3 patients in this study with B type of tympanometry curve, all three patients had mild hearing loss.
Out of the 9 patients included in this study with $\mathrm{C}$ type of tympanometry curve, moderately severe hearing loss was the most common seen in 6 patients.

The $\mathrm{p}$-value between tympanometry and pure tone audiometry is 0.000402 (p-value $<0.05$ is statistically significant), hence there is a significant statistical co-relation between the two entities.

Table 6: Co-relation between Tympanometry and Pure Tone Audiometry.

\begin{tabular}{|l|c|c|c|}
\hline \multirow{2}{*}{} & \multicolumn{3}{|c|}{ Types of Hearing Loss (On PTA) } \\
\cline { 2 - 4 } & Mild & Moderate & $\begin{array}{c}\text { Moderately } \\
\text { Severe }\end{array}$ \\
\hline Tympanometry & & & \\
\hline $\mathrm{A}_{\mathrm{s}}$ & 0 & 2 & 0 \\
\hline $\mathrm{A}_{\mathrm{d}}$ & 1 & 6 & 0 \\
\hline $\mathrm{A}$ & 3 & 1 & 0 \\
\hline $\mathrm{B}$ & 3 & 0 & 0 \\
\hline $\mathrm{C}$ & 0 & 3 & 6 \\
\hline
\end{tabular}

The average hearing loss for the patients included in our study was $47.6 \mathrm{~dB}$. The average hearing loss for the 7 patients who had mild hearing loss was $31.14 \mathrm{~dB}$, for the 12 patients who had moderate hearing loss, the average hearing loss was $49.75 \mathrm{~dB}$ and for the 6 patients who had moderately severe hearing loss, the average hearing loss was $63.16 \mathrm{~dB}$.

\section{Discussion}

In our study, 7 (28\%) patients had mild hearing loss, $12(48 \%)$ had moderate hearing loss and 6 (24\%) had moderately severe hearing loss. In the study conducted by Zheng et $\mathrm{al}^{(9)}$ on 508 patients, $104(22.4 \%)$ had mild hearing loss, 44 (9\%) had moderate hearing loss and $12(2 \%)$ had moderately severe hearing loss. The percentage of patients with mild hearing loss was in accordance with our study. In the study conducted by Sowbhagya et $\mathrm{al}^{(10)}$ on 80 patients, 28 (35\%) patients had mild hearing loss and $5(6.3 \%)$ had moderate hearing loss. Here, again the incidence of mild hearing loss was in accordance to our study.

In our study, $2(8 \%)$ patients had As type of curve, 7 (28\%) had Ad curve, 4 (16\%) had A type curve, 
3 (12\%) had B type curve and 9 (36\%) had C type curve. In the study conducted by Sowbhagya et al (10), 44 (55\%) had Type A curve, 13 (16.3\%) had As type of curve, 7 (8.8\%) had Ad type of curve, 9 (11.3\%) had B type of curve and 7 (8.8\%) had C type of curve. Only the incidence of B type curve was in agreement to our study. In the study conducted by Zheng et al ${ }^{(9)}$, $49 \%$ patients had A type of curve, $23 \%$ had B type of curve, $11 \%$ had C type of curve, $15 \%$ had As type of curve and $2 \%$ had Ad type of curve.

The inconsistency between hearing loss and middle ear disease is well documented ${ }^{(11,12)}$. Recent studies ${ }^{(13-15)}$ have suggested that as much as $64 \%$ of conductive hearing loss may go undetected by audiometric screening. The results of the present investigation support this conclusion. Doing only pure tone audiometry in cases of chronic retraction does not give us a complete idea of the status of the ossicular chain and the impact of the degree of retraction of the tympanic membrane on the hearing of a patient. Tympanometry in such cases provides us with an idea of the status of the ossicular chain and of the pressure in the middle ear as a result of the chronic retraction which can help in planning the future course of action for a patient. It acts as an adjuvant to pure tone audiometry and it helps in increasing the specificity and sensitivity of diagnosis.

\section{Conclusion}

Pure tone audiometry and Tympanometry are two of the most commonly performed investigations in an ENT OPD. They are low cost and noninvasive, and provide us with a proper picture of the degree of impairment of hearing and of middle ear pressures due to various middle ear pathologies. As proved in our study, there exists a significant statistical co-relation between the two investigations, which shows their complementary nature to each other in diagnosis of a patient. Encompassing the two, a clinician can get an idea of the ossicular chain status and of the impact of the retracted tympanic membrane on hearing, which can aid a surgeon intra-operatively. The use of the two in sync in all middle ear pathologies should be actively encouraged due to their widespread availability, low cost and non-invasive nature to help in better diagnosis of a patient to predict his or her clinical outcome with regards to hearing. Larger multicentre trials are needed to determine the co-relation between the preoperative findings, intra-operative findings and post-operative findings of pure tone audiometry and tympanometry.

Conflict of interest: The authors of this study declare no conflict of interest with regards to this study.

\section{References}

1. Sadé, J; Berco E (1976). "Atelectasis and secretory otitis media". Ann Otol Rhinol Laryngol. 85 (2 Suppl 25 Pt 2): 66-72

2. Tos, M; Poulsen G (1980). "Attic retractions following secretory otitis". Acta Otolaryngol. 89 (5-6): 479-86

3. Borgstein, J; Gerritsma TV; Wieringa MH; Bruce IA (2007). "The Erasmus atelectasis classification: proposal of a new classification for atelectasis of the middle ear in children". Laryngoscope. 117 (7): 1255-9

4. James AL, Papsin BC, Trimble K, Ramsden J, Sanjeevan N, Bailie N, Chadha NK (May 2012). "Tympanic membrane retraction: An endoscopic evaluation of staging systems". Laryngoscope. 122 (5): 1115-20.

5. MRC Multi-Centre Otitis Media Study Group (May 2001) Otol. Neurotol. 22 (3): 291-8.

6. Elzouki, Abdelaziz Y (2012). Textbook of clinical pediatrics (2 ed.). Berlin: Springer. p. 602.

7. David Jay Steele; Jeffrey Susman; Fredrick A. McCurdy (2003). Student guide to primary care: making the most of your early clinical experience. Elsevier Health Sciences. pp. 370. 
8. Onusko E, Tympanometry, Am Fam Physician. 2004 Nov 1;70(9):1713-1720.

9. Zheng W, Smith JD, Shi B, Li Y, Wang Y, Li S, Meng Z, Zheng Q. The natural history of audiologic and tympanometric findings in patients with an unrepaired cleft palate. Cleft Palate Craniofac J. 2009; 46:24-29.

10. Sowbhagya, Malligere\&Shivhare, Peeyush \& Yadav, Monu\& Sushma, Pulivarthi\& Kumar, Praveen \& Lata, S \&Shastry, Savitha. (2016). Audiometric and Tympanometric Assessment in Patients with Oral Submucous Fibrosis. British Journal of Medicine and Medical Research. 13. 1-7. 10.9734/BJMMR/2016/23615.

11. McCandless G, Thomas G: Impedance audiometry as a screening procedure for middle-ear disease. Trans Am Acad Ophthalmol Otolaryngol 1974; 78:98-102.

12. Brooks DN: Hearing screening: A comparative study ofan impedance method and pure tone screening. ScandAudiol 1973; 2:67-72.

13. Fay TH, Hockberg I, et al: Audiologic and otologic screening of disadvantaged children. Arch Otolaryngol 1970; 91:366370 .

14. Eagles E, Wishik S, Doerfler L: Hearing sensitivity and ear disease in children: A prospective study. Laryngoscope 1967; (suppl):1-274.

15. Osborn CD: Air-bone gap measurement in identification audiometry. MaicoAudiol Lib Ser 2:1975. 